\title{
CREATIVE ECONOMY: A LITERATURE REVIEW ON RELATIONAL DIMENSIONS, CHALLANGES, AND POLICY IMPLICATIONS
}

\author{
Semra Boğa ${ }^{1}$, Murat Topcu ${ }^{2}$
}

date of paper receipt:

30.09.2020.

Review Article date of sending to review:

02.10.2020.

doi: 10.2478/eoik-2020-0014 date of review receipt:

15.10.2020.

UDK 334.722:[005.32:659.23

${ }^{1}$ Adana Alparslan Türkeş Science and Technology University, International Trade and Finance Department, Turkey

${ }^{2}$ Istanbul Gelişim University, The Institute of Social Sciences, Department of Business Administration, Turkey

\begin{abstract}
In the development of the global economic system, the cumulative knowledge from past to present is of great importance. This knowledge produced by social life offers creative individuals and groups an opportunity to produce new meanings, values, contents and a source of inspiration. The influence of creative sectors in the urban life and socio-economic climate built by the industrial society created by the industrial revolution has started to increase in recent years. In the current industrial economic organization style, together with entrepreneurship, the creativity based on knowledge and technology have been added nowadays, to the land, labor and capital required for production. However, worldwide studies focus on the beneficial aspects of creative economies. There are not many studies in the literature on the past and future problems and development of the creative sector from a longterm historical perspective. In this context, it is necessary to reveal the relational ties of creative sectors with other fields; how they are positioned in national economies and how they will be analyzed. In this framework, the study aims to determine the position of the creative economy in the general economy by using the studies in the literature, to reveal the relational ties of the creative sectors with other actors, to identify the challenges in the sector, and to reveal the policy implications in creative industries. As a result of the study, it has been observed that the creative sectors are nested cellularly in all sectors of the general economy, from tourism to the automotive sector, from urban life to social networks, due to the internet, information communication technologies and digital applications. Since the outputs of the creative economy are based on the intellectual property rather than physical products, it has been determined that problems arise in the financing, accounting of services and contents introduced in this field, and measurement of the products at international standards. In addition, it has been observed that the time perception in creative sectors and the time perception of the industrial economic system differ from each other. Another important finding obtained as a result of the research is that creative economies create class differences in urban spaces and cause social segregation.
\end{abstract}

Keywords:

Creative Economy, Creative Economic Policies, Cultural Economy

JEL: O1, O3, O5, Z1. 


\section{INTRODUCTION}

Human history has developed with the adaptation of cumulative knowledge to human life. While each knowledge reveals an innovation, it eliminates the commodities in use and reproduces itself. In this context, when viewed from a long-term historical perspective, the products, services and contents created by the scientific development and knowledge of each period are creative as of their period and it is a more correct approach to define them as a creative economic activity. For example, mass production that came with the industrial revolution brought about creative products and designs as of its period. However, the creative products and services created by the industrial production style that developed with the industrial revolution have, in a sense, completed their historical life by leaving their place to digital production systems today and industrial production systems have evolved towards digital industries. From this point of view, the creative economy should be seen as a phenomenon created by the knowledge accumulated in every period, rather than just being the subject of today. In this context, today's creative products and services, which constitute the last step of historical knowledge, will become obsolete in the face of future knowledge. In other words, creative industries, which have been seen as a driving force for growth and development in recent years, will complete their lives as old-fashioned content products and services of the future. On the other hand, new creative sectors that will emerge after many years will continue the movement continuously by using today's products, services and contents in a cultural and nostalgic sense and transforming them into new values. Therefore, it would be a proper approach to see creative economies as a result of historical knowledge rather than as a part of today.

It is possible to compare the state of the creative economies expressed in terms of the future to the change created by the industrial production that emerged with the industrial revolution before. The industrial production structure, which developed with the industrial revolution, has also changed the socio-cultural and economic structures of the societies with the orderly and tightly controlled production style. Individuals that make up the society are stuck between work and home, within the urban culture and life of big cities. In other words, the collective work areas created by the industrial production style of daily life are confined within places where neat, orderly and temporal planning of every movement is made and complex residential areas, satellite neighborhoods, cities. As the concrete output of this system, a product or a commodity has been put on the market and the performance evaluations of the system are built on these outputs. On the other hand, even though no concrete product has been produced, creative social structures containing free and original ideas and spaces that create new values with their content, quality and creativity have begun to form. Creative social structure has emerged as a result of cultural searches for customized creative products, services and contents by excluding the temporal and spatial rules organized by the industrial production style, dominated by mass production and consumption hegemony. The pursuit of creating new values with new products, services and content, apart from labor, capital and labor, which are the basic production factors of the industrial ecosystem, is the source of motivation for creative ideas and creative economies. In this context, creative economies are gravitating to information and digital technologies where information is used the most. Today's society, which has been introduced to creative products, services and digital applications thanks to the complex information technologies added to social and economic systems, has undergone radical changes in many areas such as science, technology, arts, culture, education, entertainment, economy and finance.

While looking for the answer to how we can best benefit from the creative economies in today's conditions, which are called the creative economies of today and where a number of cultural and digital products are traded, it is necessary to predict which creative commodities and contents of the future knowledge will emerge and where they will evolve today. Otherwise, when the existing creativity disappears, the search for a new one will be a waste of time. In this context, the study aims to contribute to the literature on the future of creative economies by examining the existing 
potential relations of creative economies in the general economy, while at the same time complying with the principle of predicting the future, which is the basic philosophy of science.

Creativity and creative economics are subjects that have been researched and studied by different disciplines and have current scientific discussions. In general, creativity in the artistic, scientific, cultural and economic field constitutes the main axes of product, service and content applications where creativity can manifest itself. The economic dimension of creativity generally stems from its positive potential contribution to economic development (Cerisolaa, 2018). In this context, revealing the relations and ties of the creative sectors created by creativity and creativity within the general economy becomes an important issue in terms of economic policy decisions. The current literature focuses heavily on the determinants of creativity and creative sectors and their positive aspects on the general economy. For example, Sung (2015) emphasizes that the global economy, after the 1929 Great Depression, has undergone great changes and evolved into a creative ecosystem where knowledge-based, innovative, and creative ideas are at the forefront, and this is an important determining factor in the global competitive environment. Dong and Truong (2019) focused on the determinants of creative goods exports in Vietnam and found that Vietnam's creative goods exports were positively affected by the overall economies of scale and market development. Matheson (2006), examining the theoretical aspects of creative economies, underlines that the theory of creative industries "creates a broad economic framework by combining commercial realities with cultural and creative outputs". Jones and Warren (2016) state that the perception of time in the creative economy and the industrial economy is different and creative economies do not accept time pressure. Abbasi, Vassilopoulou, and Stergioulas (2017) argue that there are very strong links between creative economies and information technologies. They determined that information technologies are the driving force of the five creative sectors they examined within the scope of the project - Architecture, Art, Design, Games, Media and, e-Publishing. In the face of all these positive approaches, creative economies have turned into a strong policy discourse on a global scale after 1980, with the reports and support of international institutions in the cultural field (Duxbury et al. 2016; (UNESCO, 2013; UNCTAD, 2008; UNCTAD, 2010). There are some critical studies against the discourses and prescriptions put forward on creative economies. In other words, it is emphasized that the creative economy causes social segregation, and between the layers of society, people with creative features are separated from the rest of the society both in terms of settlement and living spaces. Also, it is criticized on the grounds that the social differentiation created by creative economies causes a rise in property prices, dubious investment returns, exploitative working conditions and, an increase in inequalities (Belfiore, 2016; O'Connor 2016; Oakley, O’Brien, \& Lee, 2013).

As can be seen, the current literature focuses heavily on the determinants of creativity and and their positive aspects on the general economy. However, there are not many studies that present a perspective to solve the problems and problems arising from the relational ties of creative economies. In this context, the study aims to contribute to the elimination of this gap in the literature by revealing the relational dimensions and challenges of creative economies. The study also highlights the economic policies designed for creative sectors.

\section{CONCEPTUAL FRAMEWORK OF CREATIVE ECONOMIES}

The importance of the creative economy has a wide coverage in academic literature, from growth to urban transformations, regional and rural-development, cultural activities to the digital media world, from computer games, cinema sector to policy documents. In this context, the concept of the creative economy is closely related to digital technologies, information-communication technologies, cultural activities, cultural tourism, and a wide range of artistic activities from painting to music, from architecture to theater. The network of relations in all these areas closely affects many economic and social activities such as urban culture, social welfare, investment preferences and 
sustainable growth (UNCTAD, 2008). After 1990, the global crises caused by financial liberalization and globalization directed countries to diversified economic activities to contribute to their growth and sustainable development. In this context, many methods and theories have been put forward to diversify the sectors that will contribute to the macro growth of countries. One of them is the concept of creative economy, which was first introduced into the literature by Howkins (2001), which claims to contribute significantly to growth. Creative economies have emerged as a result of the efforts of businesses to find less costly resources, create new markets and new jobs, and produce new content and values in terms of monetary value. The most important characteristics of creative sectors are it is based on relational learning, creativity is more visible, much information converges in different fields and advanced scientific technology is encouraged (Sung, 2015: 89). Howkins (2001) emphasizes that individual creativity is generally at the forefront in creative economies and states that these are sectors that include «intellectual property» in terms of their output. Galloway and Dunlop (2007), on the other hand, find this definition narrow-scoped and think that the creative economy has a cultural dimension. The conceptual development of the cultural economy goes back to the 1990's, earlier than the concept of the creative economy. Throsby (2008) defines the cultural economy as sectors that include creativity during its production, where "symbolic and spiritual meanings" are more prominent, and whose outputs include activities created by intellectual property. Similarly, Hesmondhalgh (2002) states that creative sectors also include sociocultural products and services by including television, radio, cinema, music recording, newspaper, magazine, book publishing, performing arts and advertising to the creative sectors. As it can be seen, although creative economies overlap with cultural economies at some points, they sometimes show complementary features. For example, from the writing to the shooting of scenes, and release on the screen of a film script, with its content and the messages it tries to give, is within the scope of cooperation of both creative economy and cultural economy. In this context, instead of examining by drawing a clear line between the sectors, examining the relational background by creating areas of cooperation and sharing will contribute more to the benefit to be obtained from these sectors. Creative economies have become the driving force of growth, thanks to the new sources of income they create with the support of growth diversification and development with the contribution of cultural economic sectors. In addition to contributing to the economies of countries in terms of creating income and gaining exports, the creative sectors (Graph 1), became one of the fastestgrowing sectors of the global economy (Graph 2) in terms of creating employment. When Graph 1 is analyzed, it is seen that the leading countries in the creative sectors are England, Germany, France, Italy, respectively.

Figure 1. Export \& Import Values in Creative Sectors (2002-2015 billion \$)

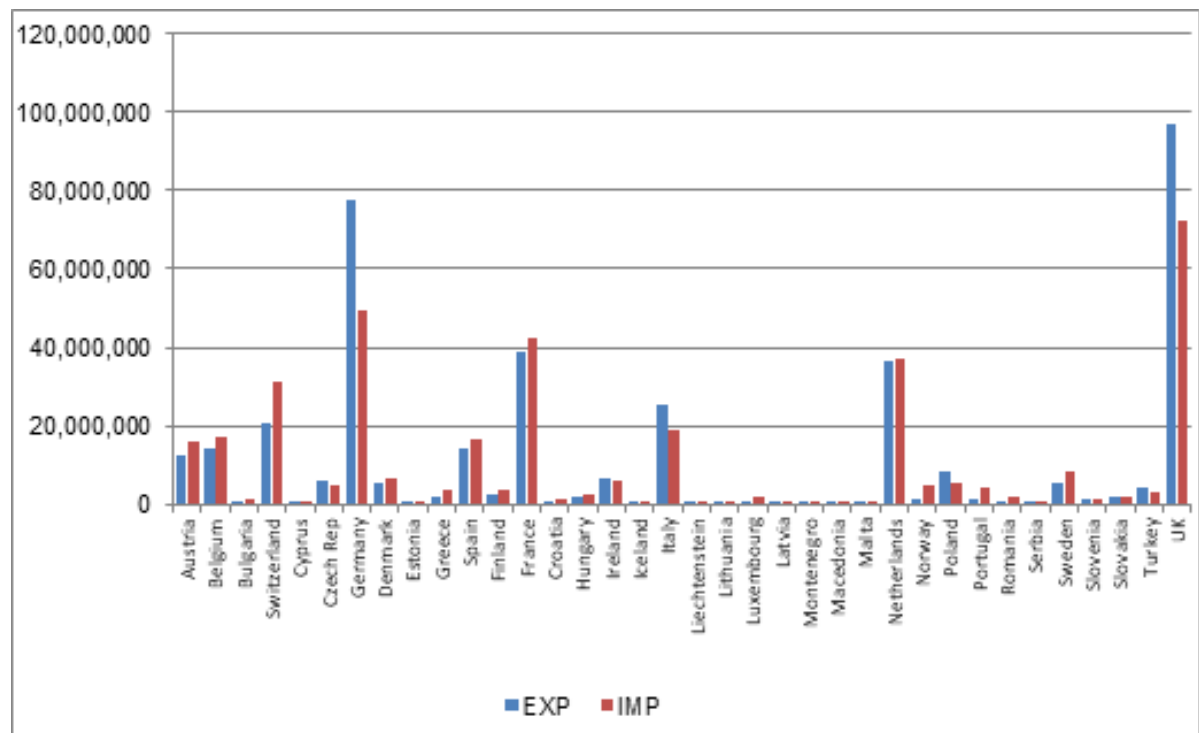


Source: UNCTAD, Creative Economy Statistics

Figure 2. The Share of Creative Economy Employment in Total Employment

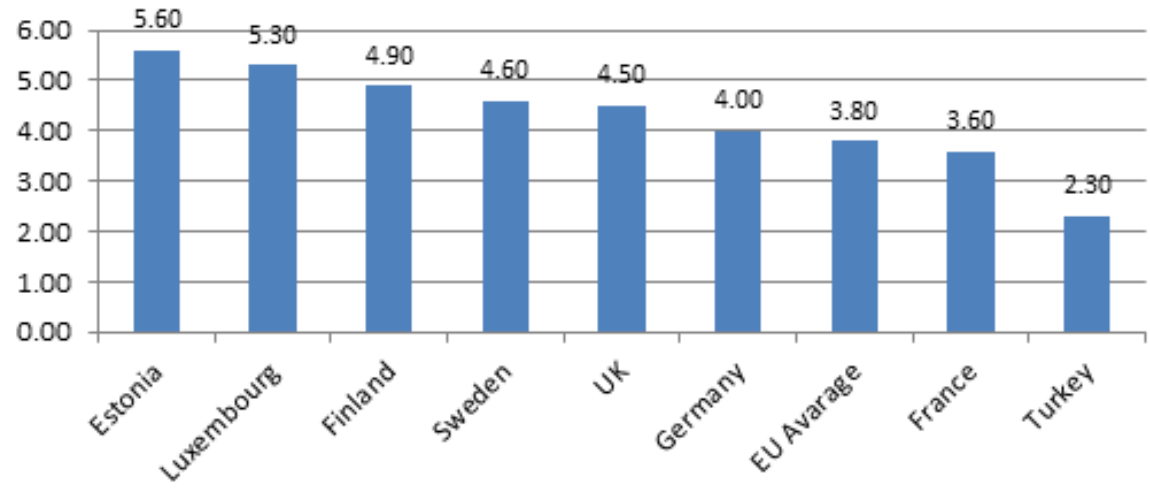

Source: Eurostat. 2019. https://ec.europa.eu/eurostat/statistics-explained/index.php?title Culture_ statistics

Creative economies are also seen as a powerful transformer for world economies with the cultural, digital and creative changes they provide (Flew, 2012). In this context, the creative economy emerges as an economic development model that puts innovation ahead, unlike classical models (Evans, 2009). On the other hand, creative economies, with the innovations and cultural values they create, contribute to the improvement of the life quality of the society and contribute to the development of regional economies (UN, 2013). Creative economies, as a new economic development paradigm, while bringing out qualitative changes in the manufacturing and service sectors, develop new approaches to cope with changing climate and demographic conditions (O'Connor, 2009). For example, the fact that museum promotions in the tourism sector are carried out without a guide with only technological devices or three-dimensional virtual museum applications reveal a qualitative change that increases the effectiveness of the promotion, in another aspect, a cinema or TV series of a particular region or territory can contribute to the solution of the demographic problems in that region. According to Howkins (2001) the creative economy consists of advertising, architecture, arts, crafts, design, fashion, film, music, performing arts, publishing, R\&D, software, toys, TV, radio and video games, and requires cooperation with many professions and business lines. The harmony between all these is provided by information technologies (IT) digital software and hardware.

\section{RELATIONAL DIMENSIONS OF CREATIVE ECONOMIES}

\subsection{INFORMATION COMMUNICATION TECHNOLOGIES (IT)}

The creative economy emerges as a result of the reflection of the creative ideas and thoughts of human beings into daily life and their transformation into economic value. Creative people are the source of the creative economy. In the creative economy, there is more «intellectual and human capital» than "physical capital». Individuals develop their creative ideas and thoughts through information and communication technologies and gain the opportunity to market them as an economic value. In other words, information processing technologies play an intermediary role in the transformation of creative intellectual capital into economic value. In this context, ITs are the driving force of the creative economy (Pearson and Saunders, 2013). While information technologies consist of hardware, software and services, communication technologies consist of electronic communication and hardware, and the share of the sector in the general economy continues to increase every year (TÜBİSAT-BİT Report, 2019: 11). One of the biggest obstacles 
to the development of creative economies is that the world's countries differ in terms of digital capability in information technologies (ICT), which is the driving force of creative economies. The reason for the differentiation in ICT ownership is the high costs of digital and technological infrastructure, and the original sin problem of less developed countries, their inability to provide resources in their national currencies. This situation increases the gap in terms of ownership of information technologies among the countries of the world. Strong multilateral efforts are needed between countries with lower ICT development and countries with high ICT development to help reduce the ICT gap to create and develop a global creative economy. The second issue is the inability to have human resources capable of using ICT. Having a high level of ICT also requires human resources who can use, maintain and develop these technologies. This situation is closely related to education. For the quality of human resources that will use ICT, which is necessary for creative economies, countries should increase the levels of their national budgets for higher education and public education expenditures.

From another point of view, the advantages of information technologies in terms of the way of doing business (logistics, distribution, vertical and horizontal integration, communication channels) and speed, contribute to the corporate and managerial performances of enterprises and affect the ties between corporate strategies and business performance. Researches show that IT is important to achieve higher performance and efficiency in the creative economy and other manufacturing industries (Sung, 2015: 90). Pearson and Saunders (2013) stated in their study that IT is an important intermediary to increase the potential of creative industries. Considering that IT is a potential driving force in terms of creative economies, the creation and development of ITs, and the availability of human resources to use these technologies in the sector, make it necessary to act together with the educational institutions operating in the field and to make new investments in the field. Similarly, it is of great importance for governments to implement policies at national and international levels that can meet the needs of rapidly changing creative sectors after the digital revolution. In this context, the governments should update and implement regulatory practices concerning the sector (property rights, copyright, fight against hijacking, taxing) according to changing conditions, implement supervisory and monitoring practices in other complex business environments with which the sector is in contact.

\subsection{INTERNET AND DIGITAL TECHNOLOGY}

In today's world, social, cultural, economic and financial activities are drawn into the scope of digital technologies day by day and human life is digitized in all aspects. In this context, technology seems to be an indispensable element in creative economies. Creative industries such as architecture, art, design, games, media, e-publishing always need internet infrastructure and advanced digital technologies. Industry representatives make directive demands for the development of future technologies in a way that can meet their requests. Thanks to advanced technology, these industries can carry out many activities from the design to the marketing of creative ideas and content at very low costs. In a sense, creative industry employees form a combination of technology and creative personality. Businesses, creative individuals, groups, associations and the public sector, which are the stakeholders of the creative sectors, have started to become more aware of creativity as it encourages growth in the economy in general (European Union Open Coordination Experts Group Culture and Creative Industries Report, 2012). In this context, actors develop themselves in parallel with the development of innovative as well as destructive and competitive technologies. Technologies are often used as a tool to increase creativity and become ubiquitous (Loveless, 2006). At the same time, new digital technologies offer solutions to specific problems of social life and culture. Thanks to the high level of interaction of the creative industry with digital technologies; 
a) digital new artistic expressions, contents and products such as digital art, digital media content, digital video contents are emerging,

b) new creativities such as three-dimensional museum web designs and gallery applications are developing,

c) digital markets, new distribution, new business models, channels and consumer groups are emerging,

d) new marketing and sales methods, tools, applications, are developing for the marketing of creative products, and service content,

e) creating a new consumer-producer interaction and developing new materials, tools and processes for creative applications, innovative communities and forms of creativity are emerging and interaction between them is increasing.

The development of digital technology and applications in recent years has facilitated access to digital technologies and tools across businesses and society. Over time, the desire and effort of individuals to access richer content and experiences in digital environments started to turn some applications that do not have material value into tangible value. The emergence of the digital media world consisting of print media and social networks, especially within the creative sector, increased competition and shortened the life of creative products. In this context, creative industries are affected by the internet, data processing, telecommunications, television, digital platforms, large data storage in digital environments, mobile communication tools and new opportunities offered by the spread of digital media. For example, all these components provide consumers with the opportunity to offer revolutionary opportunities in the promotion, distribution, marketing and consumption of creative content and products in digital environments without sharing the same physical space. Today, in addition to the physical existence, books, magazines, newspapers, music recordings, art, games and museums can reach their customers very easily everywhere and under any condition due to digital platforms (Nielsen, 2008).

\subsection{CREATIVE CITIES AND CULTURAL STRUCTURE}

The venture, which was initiated for the first time in the UK in 1998 by the Department of Culture, Media and Sports with the aim of defining creative economies and revealing their dimensions, is considered a pioneering activity in this field. Although creativity and culture are defined as different concepts in this study, it is understood that these concepts are not easy to separate from each other. For example, creativity, intellectual property, symbolic meanings attributed to the products and contents produced are seen as common components of both creative and cultural industries. Earlier, in the 1980s and early 1990s, some authors pointed out that cultural industries are the main drivers of urban renewal and change (Landry and Bianchhini, 1995; Leadbeater and Oakley, 1999; Myerscough, 1988). However, the popularization of creative industries in the wider context and as a driver for local and regional development began with Richard Florida's work on the role of creativity in regional and urban economic development (Florida, 2002). Views in which Florida draws attention to the growth rate of the creative sectors and the driving role they play in economic growth have attracted increasing attention in the literature and have started being widely included lately in the formulation of public policies by many countries (Cunningham, 2001).

Country settlements are generally built on two foundations of rural and urban culture. While the rural areas produce the basic consumer goods needed by city life, the urban population produces industrial products that are not essential for sustaining people's lives, but the whole society can consume. The basic raw material of most of these products is again provided by the rural areas. This social and economic organization form that emerged with the industrial mode of production and the social and economic organization of creative industries differ from each other. It is suggested in the literature that big cities constitute the core of creative economies (Gordon and Gibson, 2009; Dovey and Sandercock, 2002). Because while rural culture continues its activities focused on daily 
life, city culture focuses on realizing creative products, services and contents that will contribute to capitalist fund accumulation and create new values continuously. The result is, in big cities where there is a competitive environment, the creative industries are also developed. However, the creative class, which is accepted as the driving force of the creative economy created by big cities, is criticized as one of the negativities of creative economies, in that it causes an increase in social and cultural exclusion with the new style of culture and settlements it creates in cities (Macleod, 2002; Hubbard, 2004; Miles, 2005; Peck, 2005; Yeoh, 2005). In other words, it is claimed that the cultural and sociological change that creative economies will bring about in cities will create a new social layer, and in a sense will increase the formation of «new» noble classes (Gibson and Homan, 2004). According to the Marxist understanding, which looks at the issue from a class perspective, while the middle and upper layers of the creative classes formed due to creative economies benefit from activities related to creativity, the lower classes are exposed to social exclusion by being pushed out from the region (Peck, 2005).

In addition to negative views, creative cities add value to urban culture and socio-economic life with their new features, by revealing spaces where creative people can integrate and communicate with the rest of society. In this way, it mediates urban economic revival and growth. This mediation is provided by the potential contributions of certain cultural events, including new information technologies, digital media (cinema, music, film, TV series). Creative industries and the creative human profile add excitement to cities with new neighborhood relations, new cultural diversity; transform the city into a center of creative appeal and attract people from different cultures. As can be understood from the literature, while creative economies present new urban development dreams to society, on the one hand, they also affect some segments of the society negatively.

Urban architecture, settlements, neighborhoods, cultural living areas formed by the industrial production style, are changing by livening up through "creative designs and contents" and can convert cities into new centers of attraction and appeal by transforming them into places that generate new value. Change can bring exclusion of low-income segments of society and push them out of these regions (Hansen, Anderson, and Clark, 2001; MacLeod, 2002). At the same time, the real estate and housing areas in these regions add the value created by the creative industries to their own structure, thereby increasing value, especially in the real estate sector. The theater stages created by the creative culture, cinema, museums, historical places and squares, cafes, walking areas, parks, landscape and architecture add vitality to the city's appearance, as well as creating creative cities thanks to new brands. In the countryside, on the other hand, areas such as organic agriculture, natural habitats, national parks become brands, and such creative activities also form the basis of creative rural culture. In this context, the positive and negative effects that creative economies may bring to urban life, rural areas and socio-cultural structure of society should be considered as important factors to be taken into account in policies to be implemented to develop and encourage creative sectors.

\subsection{SOCIAL NETWORKS}

Social networks act as an intermediary in the promotion and distribution of creative products and the expansion of cultural values. These channels also expand the economic benefits and sphere of influence of the creative economy along the entire value chain by distribution and promotion. Social networks provided by digital technologies provide competitive advantages on a global scale with very low marginal production, distribution and transaction costs by reducing production, data storage, calculation, marketing, advertising and transmission costs. Thanks to digitalization, the link between individuals and economic activities has begun to be established through social networks over internet access. Thanks to social networks, producers are able to offer products, services and content to many geographies and markets of the world that cannot be reached with very low-cost advertising and promotion opportunities. Consumers, on the other hand, have the opportunity to compare and choose among a large number of products and contents at very low costs through 
social networks (Ahmad and Ribarsky, 2018). In this context, it is seen that digital technologies and social networks are effective on shaping consumer behavior, preferences, consumption decisions, promotion and competitiveness and entrepreneurial behavior within creative economic activities (Goldfarb, Greenstein, and Tucker, 2015). In economic activities, social media contributes at zero cost to the development and change of creative product, service and content markets by processing a large number of digital data from marketing to advertising, and to reproduction and design. Creative individuals can promote and market their content and products on a global scale at very low costs by using social networks.

Realizing the communication power between social networks and the individual, managers have accelerated their work in this field in order to penetrate global markets, to better understand the demands and requests of the individual, and to increase their market shares by offering better services (Berthon, Pitt, Plangger, and Shapiro, 2012: 261-262). Businesses can use social media (Facebook, Instagram, Twitter, Youtube, MySpace, etc.) to strengthen interaction and communication with their customers. As a result of the widespread use and popularity of social media, the online user mass significantly affects consumers' content consumption and purchasing decisions. Consumers who make a consumption or purchase decision communicate on social media and can access information about products and services both by themselves and can get information by sharing online users' experiences (Parker, 2010: 263). In this way, social media enables individuals to publish and share information, turning them into active content publishers from passive content consumers. For example, prepared by Deloitte in 2018 «Digital Bridges: Limits Exceeding the Shortest Path» from operating in Turkey in the report, 3.1 million businesses in the corresponding 1.7 million businesses in the 55\% Facebook, Instagram, WhatsApp and Facebook Messenger It is stated that it uses the Facebook application and service family. In the period when the study was focused, direct consumer expenditures, which were estimated to be triggered by Facebook platforms, were calculated as 6.3 billion TL (TUSIAD and Deloitte Digital, 2019:23). When the rate of increase in the number of social media users in the world is examined, it is seen that a significant portion of the world population, such as $45 \%$, is active social media users and access social media via mobile phones and the internet (Table 1).

Table 1. World Internet and Social Media Usage (June 2019)

\begin{tabular}{|c|c|c|}
\hline & World (Billion People) & $\begin{array}{c}\text { As Percentage of World } \\
\text { Population }\end{array}$ \\
\hline Population & 7.676 & $\% 56$ \\
\hline Mobile User Only & 5.112 & $\% 67$ \\
\hline Internet User & 4.388 & $\% 57$ \\
\hline Active Social Media User & 3.484 & $\% 45$ \\
\hline Mobile Social Media User & 3.256 & $\% 42$ \\
\hline
\end{tabular}

Source: https://wearesocial.com/global-digital-report-2019 (Authors' own construction)

Table 2. Growth Rate of World Population and Social Media Usage in the World

\begin{tabular}{|c|c|c|}
\hline & (+Million) & Percentage \\
\hline Population Growth Rate & 84 & $\% 1.1$ \\
\hline Mobile Users & 100 & $\% 2.0$ \\
\hline Internet Users & 367 & $\% 9.1$ \\
\hline Active Social Media Users & 288 & $\% 9.1$ \\
\hline Mobile Social Media Users & 297 & $\% 10$ \\
\hline
\end{tabular}

Source: https://wearesocial.com/global-digital-report-2019 (Authors' own construction)

The rate of increase in social media and internet users in the world is gradually increasing. For 
example, while the population growth rate was $1 \%$ in 2018-2019, the rate of increase in internet and social media users was 10 times faster than the population growth rate (Table 2). All these results indicate that the creative sectors, which are an important sector of the future, will show a great improvement over the internet-mobile phone-social network trio. Because nearly half of the world still has not met the internet and social media, which constitutes the potential market of the future in the marketing and consumption of the produced content.

\section{CHALLENGES OF CREATIVE ECONOMIES}

\subsection{FINANCING PROBLEM}

The "creative economy" includes more than just promoting the development of the equipment side of industries owned by an economy. Human resources, hardware, software, and how to get financing on all of them are interrelated issues. Although Howkins (2001) explains the creative economy as a concept that shows the economic consequences of an idea or an intangible content rather than physical capital, ultimately the realization of all creative ideas depends on physical capital. Many countries whose currency does not have the feature of being an international reserve currency face financing problems and cannot allocate resources to creative sectors due to the fact that their national currency cannot be used as a medium of exchange outside their national borders due to the first sinful problem mentioned above. In particular, the banking system's reduction in the cost of loans to be given to creative sectors may enable further development in this area. However, in the banking system credit risk assessment, the main factor that determines the repayment of the loan is the purpose for which the given resource will be used and what its return will be. Whereas, in creative sectors, extraordinary methods are used to realize services and projects. This practice constitutes the nature and motivation source of creative economies. In such cases, the trust level of the banks and the nature of creativity contradict; creative projects sometimes cannot be implemented or may be left unfinished due to insufficient funds. In this context, for countries to achieve the desired economic expectation from the outputs of the creative economy, besides encouraging innovations, government policies should also be put forward and necessary guarantee conditions should be established to finance them.

In creative industries, the transition from the intellectual content stage to the implementation and realization stage requires a large amount of initial capital due to the high initial costs. For example, high costs to be spent at the initial stage for a movie, radio show or magazine can contribute to increasing the consumer audience of the finished product and the attractiveness of the product. However, there is no absolute guarantee of this, and sometimes a high expenditure may not contribute to the attractiveness of the product. In terms of economic theory, although there are researches on the estimation of demand, these studies are partially uncertain. Caves (2000) also emphasizes that the uncertainty about possible demand for a newly produced content or product is a reality of the creative industries. In other words, the uncertainty in demand estimation increases even more when it comes to creative products. Because creative products are also an intellectual experience, the satisfaction level of the people who will consume them is very subjective, making it very difficult to predict how consumers will react (Caves, 2000: 3). In this context, the high level of uncertainty about demand necessitates the implementation of strategies to reduce risks in creative sectors (Picard, 2005). In other words, the main goal of businesses that produce content and products should be to provide the conditions of effective management that will increase the chance of success by reducing the uncertainties that may arise. 


\subsection{TIME PROBLEM}

The concept of time consumed in creative sectors and traditional industrial production differs in terms of content and quantity. The capitalist system managed to equalize the measure of the working time and the currency unit thanks to the industrial production system. However, the situation with creative economies is different. While the monetary value of the time spent on any creative content or product cannot be fully paid, in some cases the monetary return can be much higher compared to industrial production. In this context, the capitalist system has tightly linked time and money spent with the drive to maximize production capacity (Reisch, 2001). However, it is very difficult to establish such a relationship for creative economies. Because the incubation period required for creative ideas, products and contents to emerge can be very long (Bilton, 2014; Lubart, 2001).

Since the industrial production system focuses on wage-time-output optimization, it is oppressive in terms of regulating and accelerating employee behavior. However, the oppressive function of time remains ineffective in creative economies. For this reason, it may cause financial difficulties. Uncertainties about the incubation phase and the acceptance of content in the market make financing providers uneasy and even bring financing to a cut point after a certain threshold. As in the industrial production system, the use of time in a way that disciplines and accelerates the behavior of employees does not find a response in creative sectors. Because of their nature, creative people cannot work under routine and time pressure. Secondly, it is very difficult to find people to replace in case they quit their jobs, and even if they are replaced by others, it is very difficult for the content, product and service to get a response from the consumers. For example, if the most important actor of a TV series with a global content consumer in the cinema industry is faced with time pressure to shoot a few more episodes, and leave the series, this may end the life of the series; the substitute actor may not arouse the same interest. While time pressure increases the production capacity in industrial production style, it can sometimes have the opposite result for creative economies. The problem is the intersection point of employees and funders, which also constitutes a breaking point for the future of creative sectors. In other words, as uncertainties increase, austerity policies come into play and funders focus on supervision by increasing time pressure and compare the funds they use with the current output. This will encourage creative workers to spend time responding according to decreased and cut funds, and to fund-holders' demands rather than spending time thinking about the strategic value of the content or product. In this context, managers and financing providers operating in the creative sectors should carefully consider this issue.

The bureaucratic organizational structure of the industrial system related to wage-time-output appears as the most important obstacle in the creation of creative content and product. In the industrial production style, the aim is to increase the amount of output by keeping the employee for more production in time, thus reducing the unit costs. It creates asymmetric power for the person under time pressure and strengthens the hierarchy against the control of time through schedules, standards, clocks, calendars. However, controlling and regulating time in creative industries, thus trying to establish a temporal and output relationship for creative people can completely eliminate the value to be created. Today's developing communication, internet and network technology have removed the standard 8-hour working limits. Mobile phones, mobile applications, internet, mails, teleconferences have brought creative people to the position to produce content at all times. Thus, time and place pressure has become used for the creation of creative ideas and contents in every location and place 24 hours a day, especially in creative sectors. These developments undermine the originality of creative products and services.

Financial problems and its constraints prevent the development of creative work in longer-term due to time pressure. Because of the long-term incubation period of the content and products that creative economies try to offer and the short-term interests of the capital conflict. The necessity to harmonize the working time and duration of creative people with the time pressure of capital 
arises. According to Lefebvre (2004), unlike industrial productivity, creative activities derive their motivation from the freedom and individuality emerging in external conditions. Castree (2009) focuses on the abstract power of the clock in the temporal and spatial construction of capitalism. Castree's argument is that one of the tools used by the capitalist form of organization to control space and social relations is time. The conclusion from this is that creative people are rushed by time pressure and capitalist production processes (Jones and Warren, 2016). In this context, policies to intersect the time perception of creative people and the appetite of fund providers for shortterm high returns at the optimum point are needed. The public sector can play an intermediary role in establishing the optimum balance between the two. For this purpose, the support of some creative sectors and projects by central governments or local government budgets will sometimes contribute to public returns, provide the desired social benefit from the products, services, and contents produced by the sector, and help the development of the sector. Creativity has become an important element for the post-industrial economies of the future to generate new values and contents. Creative and cultural industries are seen as key sectors for the recovery and development of the backward regions of countries. Florida (2002) argues that in order to increase the economic efficiency of cities, creative people should be encouraged and induced to cities.

\subsection{SOCIAL STRATIFICATION AND THE PROBLEM OF EXPLOITATION}

Creative culture and the creative industry differ from industrial products because they are the output of people's self-thinking. In this context, there are criticisms that intellectual contents and products lead to the exploitation of creative people due to inadequate regulations for the protection of property rights. From another perspective, it is known that creative sectors produce cultural change and new material values in cities. The new material values produced in this context will lead to the emergence of new layers in the social structure, and the cultural change to be experienced in the city life will cause regional differentiation in the socio-cultural and economic structure of the city. For example, let's assume that a creative movie and series emerges in a city that attracts attention and is consumed all over the world. The change in the creative sector will lead to the emergence of famous people in that city, the formation of high income groups, the emergence of new areas of influence as a result of these people's use of their media and networks, and cultural changes such as new restaurants and luxury settlements depending on the income obtained. Local governments will naturally focus on investments and services for the environments where these people are located in order not to be exposed to their reaction. This situation will cause the formation of new social layers in city life, deterioration of income distribution, and socio-cultural segregation in the social structure. In this context, the discourse, suggestions and policies of creative economies and creative culture have been criticized by academic circles (Belfiore, 2016; O'Connor, 2016; Oakley, O'Brien, and Lee, 2013). When creative economies are viewed from this perspective, it is seen that there are claims that it causes stratification in the society, increases property prices, forms exploitative working conditions and increases income inequality. As a justification for this, it is shown that it will become a necessity for talented people who have a creative workforce to continue their creative abilities in all circumstances at the end of a certain period of time in order to sustain their privileges (Oakley and Ward, 2018). In other words, creative people will have to accept the existing working conditions in order not to lose the privileged position they have attained, and they will endure the exploitation of their creativity, which is the main source of their privileges.

\subsection{MEASUREMENT PROBLEM}

In order for economic activity to be measured and its results to be accepted on a global scale, a full definition and classification on which there is international consensus must first be made. Since industrial economies are focused on physical output and sales, it is very easy to define and measure 
the goods and services produced in this system. However, the fact that the products, services and contents offered in the creative sectors are in some cases within the scope of intellectual property, in other words, do not correspond to a physical product, and the creative sectors are intertwined with many branches of the economy such as the cultural economy and the digital economy constitute barriers to their measurement. In addition, it is very difficult to analyze how creative human resources, which is the source of intellectual property, are included in the creation of a new product and to evaluate the productivity and effectiveness of these creative talents. The lack of a standardized measurement method for creative industries by both national and international reliable organizations or the countries' own institutions, and the fact that the data set is not kept makes it difficult to measure and compare creative economic activities.

About the subject, according to the UK Ministry of Culture, Media and Sports According to Creative Industries - Mapping Document 1998 (Creative Industries - Mapping Document 1998) published on the official website, the classification of creative industries was divided into 13 subsectors for the first time such as advertising, architecture, arts, crafts, design, fashion, cinema, film, entertainment software, music, performing arts (performing arts) broadcasting, software, television and radio. However, the classification, which includes the determination of 13 sub-sectors put into practice by the UK, is criticized for not including some sectors due to the ambiguity in the concepts of "creativity» and «intellectual property», which form the theoretical framework of the creative economy. The common features of the 13 sub-sectors classified are that «they have emerged thanks to individual creativity, skills and talent and have the potential to create economic value through intellectual property production». The concept of intellectual property is defined as «the value of an idea that is protected under copyright, patent, trademark or other legal or regulatory mechanism and thus cannot be imitated or transformed into a commercial privilege without the permission of its producer» and constitute the essence of the conception of creative industries.

The second problem regarding the measurement of creative economies is the calculation of the cultural economy within creative economies by evaluating them as the same concepts due to the tight transition between the creative economy and the cultural economy as stated above. The third problem with measurement is that the concept and framework of the creative economy cannot be drawn, and the lack of an internationally agreed transparent classification method. The reasons stated above cause each country to use a specific classification and measurement method. Despite all these difficulties, the share of the creative economy in the general economy is tried to be measured through data such as foreign trade made by countries and the number of employees in the creative sectors, based on current classifications. Despite all this, creativity and creative economic activities are carried out simultaneously in all industries of the national economy. Measuring creative economic activities in other industries can only be revealed by exposing the number of employees and the values they produce by creative individuals in other sectors, in other words, by determining the "creative intensity of the economy». The creative intensity of the economy is calculated by the percentage of people working in creative professions among all sectors in the general economy. For example, designing is a sub-branch of the creative industry. The ratio of designers working in the automotive sector to the people working in that sector gives the creative intensity of the automotive industry. This measurement enables the identification of the industrial branches that are rich in creativity. The individual benefits of the products and services produced in the creative sectors that cannot be calculated in monetary terms, such as the pleasure of music or design, performing arts, designed play, have not been fully developed to include concepts such as psychological relaxation, happiness and satisfaction into GDP.

\subsubsection{ACCOUNTING OF THE CREATIVE ECONOMY}

Creative economies are the result of the activity of creative individuals and groups. In other words, it has different features compared to other sectors due to the content and values created by the 
human factor. The most important difference is that individual creativity forms the basis of creative economy. This is based on individual knowledge, skills and abilities. Unlike the mass production style of the industrial economy, the labor input used to create a creative product is directly related to the personal qualities and vision of creative individuals. This feature of the creative economy makes it difficult to evaluate a product or content produced and to measure consumer approaches and perceptions about the quality of a product put on the market and to establish standardization related to it. In the general economy, the creative sector is mostly composed of intangible assets and values such as fine arts including television, radio, cinema, music recording, newspaper, magazine, book publishing, performing arts, and advertising. For this reason, it is quite difficult to estimate the monetary amounts of creative products, services and contents such as an increase in assets in terms of the balance sheet, decrease in value, book value and scrap value. In this context, it becomes difficult to evaluate and report the products, services and contents produced by creative individuals through generally accepted standard accounting systems and reports. For example, according to general accounting standards, although a commodity is depreciated over time due to amortization, the artistic value of an artwork or the number of users of a digital game increases over time. Therefore, it becomes almost impossible to use standard accounting and reporting procedures in determining the value of a product, service or content produced by creative sectors.

\section{CREATIVE ECONOMIC POLICIES AND RECOMMENDATIONS}

Innovation and creativity are widely used in many national development strategies as variables that will contribute to growth. For this reason, many countries develop policies to support and develop their creative industries, local creative production and consumption (Pratt, 2009). The efforts and policies to stimulate the creative economy, which first emerged in developed countries and then spread into developing countries, have long pioneered the development of creative industries in Asian countries such as Singapore, Korea, and China, and play an important role in the growth and development of these countries (UN, 2004). In North America, creative economic policies are mostly used to create new value by reviving neighborhoods that are underdeveloped and with low industrialization (Gibson and Homan, 2004; Hall, 2000; Pratt, 2008; 2009). Developing countries mostly focus on using the comparative advantages of their cultural products in production costs (Evans, 2009) instead of producing new knowledge and innovation (Kong, Gibson, and Khoo, 2006), thus, putting forward their traditional values. Because investing in creative sectors requires technology; it is seen as risky in terms of marketing the content and product and getting consumers' acceptance. On the other hand, the lack of legal and supervision on intellectual property and copyrights in developing countries and the lack of awareness and consciousness of the society on this issue cause the values and products created by creative economies not to be seen as private goods (Howkins, 2001; UNCTAD, 2010). For this reason, policies that encourage the creative economy applied in these countries do not give the same results as the developed countries. For example, the use of a product or content while ignoring copyrights can lead to the complete destruction of the creative sector in that field. For this reason, the concept of the creative economy remains only discourse in developing countries. Social preferences, institutional structures, the development of social awareness and the effectiveness of legal regulations are what will drive the creative economy from discourse to action. In this context, differences in social preferences and institutional arrangements between countries affect the institutionalization of creative economic policies and ideas, so the managerial and institutional structures of traditional businesses and creative businesses differ (Rodrik, 2008). In the majority of developing countries, traditional businesses are considered as creative industries due to differences in concept, knowledge and application. The fact that creative and traditional businesses have different characteristics and different potentials cause them to produce different outputs and value creation processes. Therefore, different approaches and policies are required to both. For the development of creative economies, ensuring the adoption of 
creative economies at the local level, implementing participatory actions that increase cooperation among local stakeholders, incorporating space-based creative ideas into local development projects, and establishing expert forums in order to eliminate the lack of information of intermediaries, increasing the potential cooperation between universities and creative sectors are recommended (Fahmi, McCann, and Koster, 2017). Many countries around the world have realized the value created by the relational dimension of the creative economy and its contribution to sustainable socio-economic development, and in this context, countries such as the USA, the EU and the UK have implemented policies to develop and strengthen their creative economies in the post2000 period (Esen and Atay, 2017). In other countries of the world, on the other hand, creative economy conferences are held regularly, and many countries include the cultural economy and products, services and contents produced by the creative sectors in their bilateral trade agreements. For example, Caribbean countries have included cultural industries in their free trade agreement with the EU, Indonesia established the Ministry of Tourism and Creative Economy in 2011, and Lebanon's capital Beirut implemented its creative economy strategy to culturally revitalize the multicultural and multi-religious city center. (De Beukelaer, 2014: 233)

Figure 3. Comparison of Import-Export-Total Trade Volume in Creative Sectors (2002-2015 billion\$)

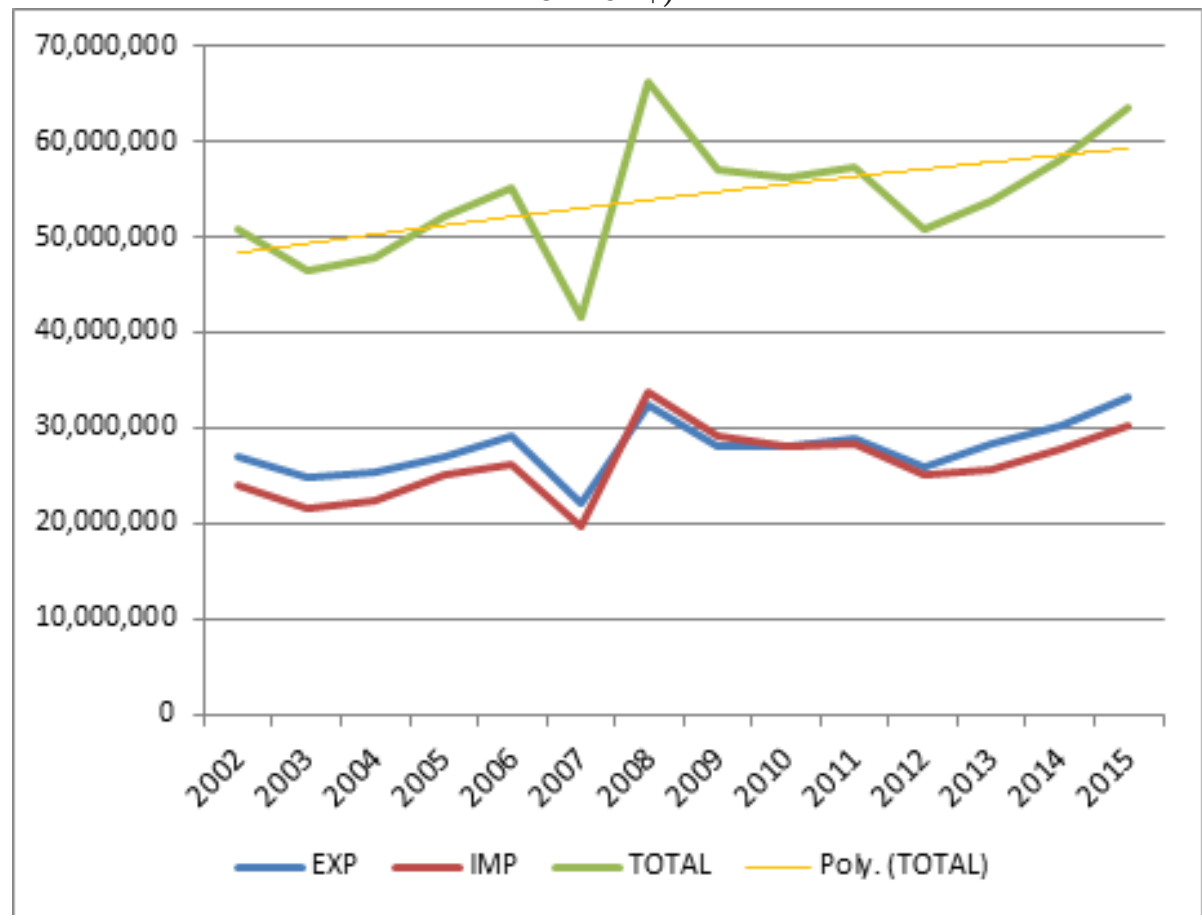

Source: UNCTAD, Creative Economy Statistics

The creative sectors, which will have an important place in the world ecosystem in the future, can be understood both from the value they add to the country's exports (Graph 1), and their contribution to employment (Graph 2) and from the studies in the literature. If it is necessary to predict the future of creative sectors, it is seen that its contribution to both employment and trade volume in the world ecosystem is in an increasing trend. This determination is confirmed by the general trend towards the increase in the import, export and total trade volume (excluding the 2008 crisis year) of the product, services and contents produced in the creative sectors between 2002 and 2015 belonging to 32 countries indicated in Graph 1 (Graph 3).

It is observed that creative sectors have created a brand new economic order and functioning style and that they will reveal new paradigms in human life and career life, from businesses to the public sphere, from education planning to evaluation, and to the planning of the cities where they live. In this context, since the influence and position of creative sectors in general economies will 
come to the forefront, it becomes important for countries what kind of policy proposals they will put forward to develop their creative sectors in macro terms and to create their roadmap policy documents. For this purpose, the answer to the following question should be sought first. What is the inspiration source of creative industries? When the general literature is examined, "creative individuals " constitute the source of inspiration of the creative sectors. Then, it is necessary to make micro-planning in order to achieve macro goals in creative sectors. For this reason, first of all, creative people should be encouraged and revealed, then creative groups should be formed, and finally, creative culture and climate should be made dominant throughout the country.

First of all, starting with children's education, the elimination of creativity at a young age should be prevented, and a climate that will encourage creativity in schools should be created. The education system should be removed from the position that memorizes and teaches the knowledge, and the relational learning method that seeks information and generates new knowledge and values by associating them with information in other fields should be adopted. For this purpose, the mental transformation of the educators should be ensured first. Afterward, encouraging entrepreneurial capital to produce products, services and content that will be created by the creative climate, establishing technological infrastructure with the support of the public and universities for this purpose, and eventually introducing and marketing the resulting products, services and content, and related macro level policy documents starting from the micro must be put forward.

Figure 4. The Creative Nexus

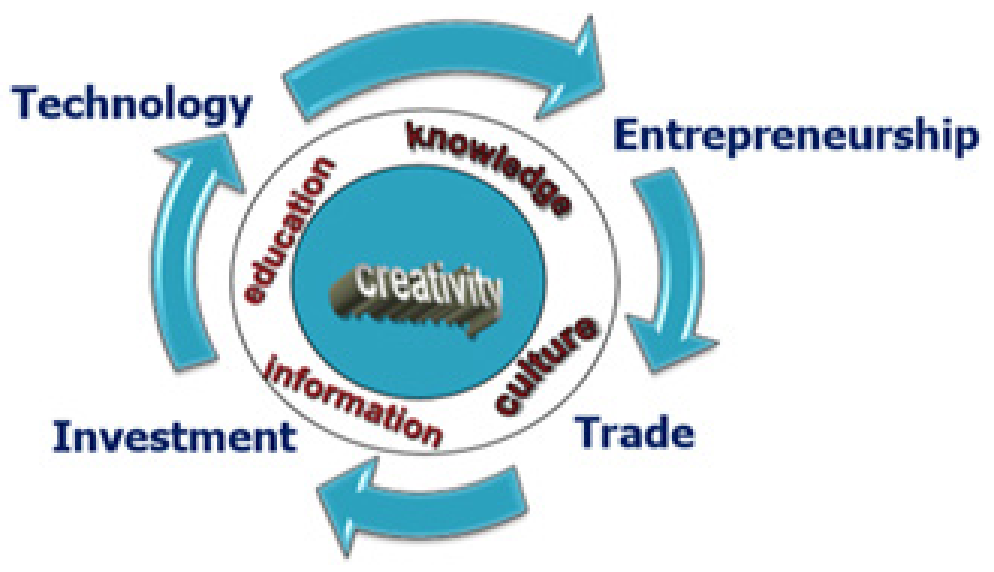

Source: UNCTAD, Dos Santos, 2007

With the industry 4.0, which is the driving force of the rapidly developing digital economies in recent years, artificial intelligence robots will fulfill the work of humans in many areas. This means that many professions will disappear in the very near future. However, it seems unlikely that artificial intelligence robots can perform many jobs in creative sectors. For this reason, creative sectors, which make a significant contribution to employment, can absorb the unemployment caused by digital economies, again by creative people themselves using information technologies and digital technology. In this context "it can be argued that the main fuel of the 20th-century economy is petroleum, and the fuel of the 21 st century is creativity. 


\section{CONCLUSION}

Even though creativity and creative economic activities have been conceptualized today in the post-2000 period, in the historical process, they have been a recurrent process in motion as a result of the adaptation of cumulative information to human life in terms of content. In other words, the product, service, content and value created by every new information is also a creative economic activity. While new information added to the information used over time creates new creative products and services, it enables the old ones to disappear or to redesign them as nostalgic and cultural. Creative individuals and intellectual property rights are the source of inspiration for creative economic activities. Although a classification has been made as creative sectors in the literature, creative individuals operate cellularly within all sectors in the general economy.

In the national economy, each creative industry operates independently, as well as clustering like cells into different industries. In this context, creative industries are in close contact with many areas of socio-cultural life in a wide range of fields through digital technologies, information communication technologies, cultural activities, cultural tourism, artistic activities, social networks, city and urban life. Creative cities and cultural structures with which creative sectors are related play a role in encouraging the emergence of creativity and the clustering of creative individuals in a particular region or city. While rural culture continues its activities focused on daily life, big cities dominated by urban culture and a competitive environment contribute to the development of creative industries. However, the new style culture and settlements created by the creative class in big cities are criticized as one of the negativities of creative economies, in that they cause an increase in social and cultural exclusion within the social layers.

Technology is considered as an indispensable element in creative economies. Creative industries such as architecture, art, design, games, media, e-publishing always need internet infrastructure and advanced digital technologies. Internet, digital technologies and ICTs enable the design of creative products, services and content, and the interaction of these products with other sectors. Social networks undertake the promotional distribution function of creative products. The widespread use of the internet, computing, telecommunications, television, digital platforms, large data storage in digital environments, mobile communication tools and digital media, provides the opportunity to present to consumers the revolutionary opportunities at very low costs for the promotion, distribution, marketing and consumption of creative contents and products in digital environments without sharing the physical space. In this context, the development and dissemination of digital technologies, ICTs and social networks become important in terms of providing the economic benefit expected from creative sectors.

Creative industries have three main problem areas. The first is the financing problem. Because the realization of all creative ideas is based on physical capital and a creative idea requires a large amount of initial capital in the implementation and transformation of a product into service and involves uncertainty. Many countries whose currency is not an international reserve currency encounter financing problems and cannot allocate resources for creative sectors. The banking sector, on the other hand, is reluctant to provide loans to creative sectors. Because, in the credit risk assessment, the banking system looks at the repayment of the loan, the purpose for which the given resource will be used and what the return will be. At this point, the trust level of the banks and the uncertainty in the nature of creativity contradict, and creative projects sometimes cannot be implemented or are left unfinished due to lack of resources. In this context, in order for countries to achieve the desired economic expectation from the outputs of the creative economy, besides encouraging innovations, government policies should also be put forward and necessary guarantee conditions should be established to finance them.

Another problem is the time issue. Because the long-term incubation period of the content and products that creative economies try to offer and the short-term interests of the capital conflict. Financial problems and its constraints prevent the development of creative work in longer-term due 
to time pressure. Since the industrial production system focuses on wage-time-output optimization, it is oppressive in terms of regulating and accelerating employee behavior. However, the oppressive function of time remains ineffective in creative economies. For this reason, it may cause financial difficulties. Uncertainties about the incubation phase and the acceptance of content in the market make financing providers uneasy and even bring financing to a cut point after a certain threshold. The new material values created by the creative industries cause the emergence of new layers in the social structure and regional differentiation in the socio-cultural and economic structure of the city in urban life. To put it more clearly, creative industries cause the formation of high income groups in the city, the emergence of new areas of influence by the use of social media and networks of these groups, and cultural changes such as new restaurants and luxury settlements on a regional scale according to the income distribution in urban life. Local governments naturally focus on investments and services in the environment where these groups are located in order not to be exposed to the reaction of these groups. This situation is criticized because it causes the formation of new social layers in urban life, the deterioration of income distribution, and sociocultural segregation in the social structure. Taking into account the reduction of negativity in the formulation and development of creative economic policies, avoiding regional differences and social stratification that may arise from creative sectors can contribute to the formation of social peace. The fact that the concept and framework of the creative economy cannot be determined completely, the absence of an internationally agreed transparent classification method prevents the formation of an international standard for the measurement and classification of the creative economy. Revealing the different relations and interactions of creative economies with other sectors through other studies may contribute to reducing measurement problems and overcoming other problems mentioned above. Many countries develop new creative economic policies in this context and even establish ministries of creative economies in order to institutionalize these policies. In order to develop their creative sectors and achieve the goals they want, countries, starting with uncovering the creative personality, need to create and allocate resources for the macro-level graded policy documents, especially in education. 


\section{REFERENCES}

Abbasi, M. Vassilopoulou P., \& Stergioulas L. (2017). Technology Roadmap for the Creative Industries. Creative Industries Journal, 10(1), 40-58.

Ahmad, N. \& Ribarsky, J. (2018). Towards a Framework for Measuring the Digital Economy. OECD Headquarters, Paris, France, 19-21.

Belfiore, E. (2016). Cultural Policy Research in the Real World: Curating "Impact", Facilitating "Enlightenment.". Cultural Trends, 25(3), 205-216.

Berthon, P. R., Pitt, L. F., Plangger, K., \& Shapiro, D. (2012). Marketing Meets web 2.0, Social Media, and Creative Consumers: Implications For International Marketing Strategy. Business Horizons, 55, 261-271.

Bilton, C. (2014). Uncreativity: The Shadow Side of Creativity. International Journal of Cultural Policy, 2, 153-67.

Castree, N. (2009). The Spatio-Temporality of Capitalism. Time \& Society, 18, 26-61.

Caves, R. (2000). Creative Industries: Contracts between Art and Commerce. Cambridge, MA: Harvard University Press.

Cerisola, S. (2018). Multiple Creative Talents and their Determinants at the Local Level. Journal of Cultural Economics, 42, 243-269.

Cunningham, S. (2001). From Cultural to Creative Industries: Theory, Industry and Policy Implications. Culturelink (Special Issue), 9-32.

De Beukelaer, C. (2014). Creative Industries in Developing Countries: Questioning Country Classifications in The UNCTAD Creative Economy Reports. Cultural Trends, 23(4), 232-251.

Dong, C. V. \& Truong, H. Q. (2019). The Determinants of Creative Goods Exports: Evidence from Vietnam Journal of Cultural Economics, July 2019.

Dovey, K. \& Sandercock, L. (2002). Hype and Hope: Imagining Melbourne's Docklands. City, 6(1), 83-101.

Duxbury, N., Hosagrahar, J., \& Pascual, J. (2016). Why Must Culture Be at the Heart of Sustainable Urban Development? Barcelona: United Cities and Local Governments.

Esen, Ü.B. \& Atay, Ö. (2017). Ekonominin Yeni Yüzü: Yaratııı Ekonomi. Sosyoekonomi, 25(33), 5980 .

Evans, G. (2009). Creative Cities, Creative Spaces, and Urban Policy. Urban Studies, 46, 1003-1040.

Fahmi, F. Z., Koster, S., \& McCann, P. (2017). Creative Economy Policy in Developing Countries: The Case of Indonesia. Urban Studies, 54(6), 1367-1384.

Flew, T. (2012). The Creative Industries, Culture and Policy, Sage Publication, London.

Florida, R. (2002). The Rise of the Creative Class and How It's Transforming Work, Leisure, Community and Everyday Life. Basic Books, New York NY

Galloway, S \& Dunlop, S (2007). A Critique of Definitions of the Cultural and Creative Industries in Public Policy. International Journal of Cultural Policy, 13(1), 17 -31.

Gibson, C. \& Homan, S. (2004). Urban Redevel Opment, Live Music and Public Space: Cultural Performance and The Re-Making of Marrickville. International Journal of Cultural Policy, 10(1), 69-86.

Goldfarb, A., Greenstein, S.M., \& Tucker, C.E. (2015). Economic Analysis of the Digital Economy. National Bureau of Economic Research, 1-17.

Gordon, W. \& Gibson, C. (2009). Chris Creative Small Cities: Rethinking the Creative Economy in Place, Urban Studies, 46(5-6), Special Issue: Trajectories of the New Economy: Regeneration and Dislocation in the Inner City, 1223-124. 
Hall, P. (2000). Creative Cities and Economic Development. Urban Studies, 37(4): 639-649.

Hansen, A. L., Anderson, H. T., \& Clark, E. (2001). Creative Copenhagen: Globalization, Urban Governance and Social Change. European Planning Studies, 9, 851-858.

Hesmondhalgh, D. (2002). The Cultural Industries. London: SAGE.

Howkins, J. (2001). The Creative Economy: How People Make Money From Ideas. Penguin, London

Hubbard, P. (2004). Revenge and Injustice in the Neoliberal City: Uncovering Masculinist Agendas, Antipode, 36(4), 665-686.

Jones, P. \& Warren, S. (2016). Time, Rhythm and the Creative Economy. Transactions of the Institute of British Geographers, 41, 286-296.

Kong, L., Gibson C., \& Khoo L. (2006). Knowledges of the Creative Economy: Towards A Relational Geography of Diffusion and Adaptation in Asia. Asia Pacific Viewpoint, 47(2), 173-194.

Landry, C. \& Bianchini, F. (1995). The Creative City. London: Demos

Leadbeater, C. \& Oakley, K. (1999). The Independents: Britain's New Cultural Entrepreneurs. London: Demos.

Lefebvre, H. (2004). Rhythmanalysis: Space, Time and Everyday Life. Continuum, London

Loveless, A. M. (2006). Literature Review in Creativity, New Technologies and Learning. Report 4, Future Lab, School of Education. University of Brighton.http://citeseerx.ist.psu. edu/ viewdoc/download?doi=10.1.1.392.2297\&rep=rep1\&type=pdf

Lubart, T. I. (2001). Models of the Creative Process: Past, Present and Future. Creativity Research Journal, 13, 295-308.

MacLeod, G. (2002). From Urban Entrepreneurialism to a 'Revanchist City'? On The Spatial In justices of Glasgow's Renaissance. Antipode, 34, 602-624.

Matheson, B. (2006). A Culture of Creativity: Design Education and the Creative Industries. Journal of Management Development, 25(1), 55-64.

Miles, M. (2005). Testing the Rhetoric of Culture Ally Led Urban Development. Urban Studies, 42, 889-911.

Myerscough, J. (1988). The Economic Importance of the Arts in Britain. London: Policy Studies Institute.

Nielsen, T. (2008). The ERIBA Model: An Effective and Successful Policy Framework for the Creative Industries. The Knowledge Foundation. http://www.norden.ee/images/loo memajandus/ info/loome/tobias_nielsen_eribamodel2008.pdf

Oakley, K., O’Brien, D., \& Lee, D. (2013). Happy Now? Well-Being and Cultural Policy. Philosophy \& Public Policy Quarterly, 31(2), 18-26.

Oakley, K. \& Ward, J. (2018), Creative Economy, Critical Perspectives. Cultural Trends, 27 (5), $311-$ 12.

O'Connor, J. (2016). After the Creative Industries: Cultural Policy in Crisis. Law, Justice \& Global Development, 1, 1-18.

O'Connor, J. (2009). Creative Industries: A New Direction? Int.J.Cult. Policy, 54 (4), 387-402.

Parker, C. (2010). 301 Ways to Use Socialmedia at Boost Your Marketing. New York: McGraw-Hill.

Peck, J. (2005). Struggling with the Creative Class. International Journal of Urban and Regional Research, 29, 740.

Pearson, K.E. \& Saunders, C.S. (2013). Strategic Management of Information Systems, John Wily \& Sons, Singapore

Picard, R. (ed.) (2005). Media Product Portfolios: Issues in Management of Multiple Products and Services. Mahwah, NJ: Lawrence Erlbaum Associates.

Pratt, A. C. (2009). Cultural Economy. In: Kitchin, R. \& Thrift, N. (eds). International Encyclopedia 
of Human Geography, Oxford: Elsevier.

Pratt, A. C. (2008). Innovation and Creativity. In: Hall, T., Hubbard, P., \& Short J. R. (eds) The SAGE Companion to the City. London: SAGE Publications Ltd.

Reisch, L. A. (2001). Time and Wealth: The Role of Time and Temporalities for Sustainable Patterns of Consumption. Time \& Society, 10, 367-85.

Rodrik, D. (2008). One Economics, Many Recipes: Globalization, Institutions, and Economic Growth. Princeton: Princeton University Press.

Sung, T. K. (2015). The Creative Economy in Global Competition. Technological Forecasting\& Social Change, 96, 89-91.

Throsby, D. (2008). Modelling the Cultural Industries. International Journal of Cultural Policy, 14(3), 217-232.

TÜSİAD and Deloitte Digital (2019). E-Ticaretin Gelişimi, Sınırların Aşılması ve Yeni Normlar Raporu, (Editörler, Ebru Dicle, Yasemin E. Avc1, Leyla Gülyurt)

TÜBİSAT-BİT 2019 Raporu; http://www.tubisad.org.tr/tr/bilgi-bankasi/sunumlar-liste/TUBISADRaporlar/40/0/0 https://afyonluoglu.org/bit-kilavuzlar/

United Nations (UN) (2004). Creative Industries and Development. São Paulo: United Nations UNCTAD (2010) United Nations Conference on Trade and Development Creative Economy Report 2010: A Feasible Development Option. Geneva: United Nations.

UNCTAD (2008). United Nations Trade and Development Conference, Creative Economy Report-2008. https://unctad.org/en/docs/ditc20082cer_en.pdf

UNESCO (2013). Creative Economy Report 2013. New York: United Nations.

United Nations (2013). Creative Economy Report, United Nations, Geneva and New York.

Yeoh, B. (2005). The Global Cultural City? Spatial Imagineering and Politics in the (Multi) Cultural Marketplaces of South-East Asia. Urban Studies, 42, 945-95.

European Union Open Method of Coordination Expert Group on Cultural and Creative Industries. (2012). "How Can Cultural and Creative Industries Contribute to Economic Transformation Through Smart Specialisation?" Policy Handbook on How to Strategically Use the EU Support Programmes, Including Structural Funds, to Foster the Potential of Culture for Local, Regional and National Development and the Spill-over Effects on the Wider Economy? Accessed April 2016. http://s3platform. jrc.ec.europa.eu/documents/20182/84453/120420_ CCI_Policy_Handbook_(FINAL).pdf

Creative Industries - Mapping Document (1998)

https://www.gov.uk/government/publications/creative-industries-mapping-documents-1998 